\title{
N91-18306
}

\section{DIAMONDLIKE CARBON APPLICATIONS IN INFRARED OPTICS AND MICROELECTRONICS}

\author{
J.A. Woollam, B.N. De, S. Orzeszko*, N.J. lanno and P.G. Snyder (a) \\ S.A. Alterovitz and J.J. Pouch (b) and \\ R.L.C. Wu and D.C. Ingram ${ }^{* *}$ (c) \\ (a) Center for Microelectronic and Optical Materials Research, and \\ Dept. of Electrical Engineering. University of Nebraska \\ Lincoln, NE 68588-0511, USA \\ (b) NASA Lewis Research Center, Cleveland, OH 44135, USA \\ (c) Universal Energy Systems, Dayton, OH 45432, USA
}

\section{Introduction}

Numerous authors worldwide have prepared diamondlike carbon (DLC) for various potential applications [1]. The present chapter reviews work done, by ourselves and others on an important aspect of the use of DIC as a protective coating in rarsh environments. This article contains new material not previously published, as well as material re-presented, but with a new perspective. The motivation for the original studies was tise potential appliceion of DIC on infrared transmitting optics $[2 ;$, ard as protective coatings in microelectronics [3].

There are three sub-topics in this chapter. The first is a description of the preparation of DLC on seven different infrared transmitting materials, and the possibility of using DLC as an anti-reflecting coating at commonly used wavelengths [4]. DIC doesn't bond easily to all materials, and special techniques for bonding have been found both by ourselves and others.

The second topic deals with how well DLC will protect a substrate from moisture penetration. This is an important aspect in numerous uses of DLC, including both infrared optics and integrated circuits [5].

The third sub-topic also involves ar environmental aspect, namely the effect of particulate impact on film performance and integrity. For example, an infrared coating may be exposed to a space environment or to conditions of blcaing sand or water [2]. It is important to know how well DLC mair:ains its integrity.

* Nov: at Nicholas Copernicus University, Torun, Poland.

**Now at Whickham Ion Beam Systems, Itd., :evcastle-Upon-Tyne, Great Britain. 
II. DLC on Infrared Transmitting Materials

Several different infrared substrates were used, including lexan, silicon, fused silica, $\mathrm{KG}-3$ glass, $\mathrm{BK}-7$ glass, $\mathrm{ZnS}, \mathrm{ZnSe}$, heavy metal fluoride glass, GaAs, and Ge.

Extensive depositions were carried out using four different systems, including direct ion beam, and three parallel plate capacitively coupled plasma chamber designs.

\section{A. Ion-Beam Deposition}

The schematic diagram of the system used to ion beam deposit DIC films is shown in Figure II-1. It consisted of four sections: the ion source, the gas inlet system, the vacuum system, and the target fixture. The ion source was a $2.5 \mathrm{~cm}$ Kaufman source made by Ion-Tech Inc. Figure II-2 shows a schematic circuit diagram of the source. The ion beam was produced by a plasma discharge and a typical ion current was 10ma. The ion kinetic energy used in the deposition could be varied from 100 to $1500 \mathrm{eV}$. The beam profiles of the ion source were extensively characterized under various conditions such as ion energy, and external magnetic and

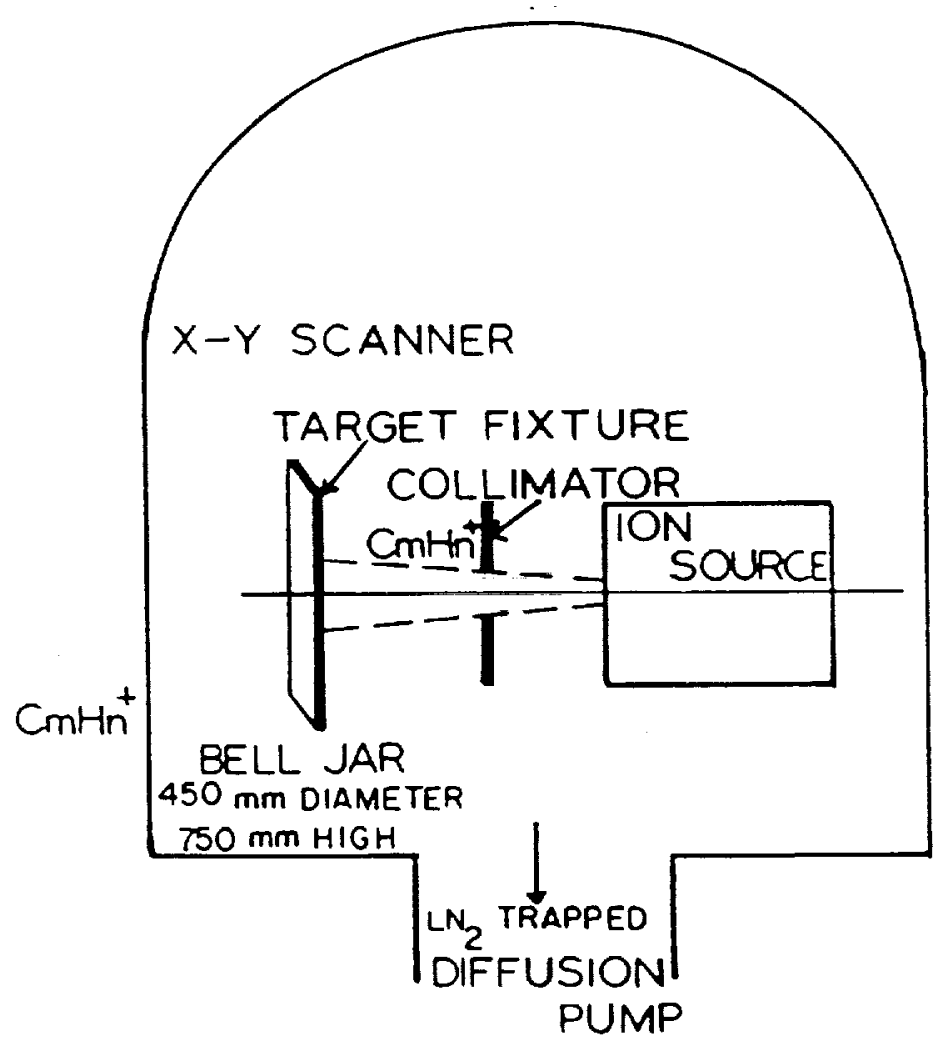

FIGURE $11-1$. Schematic drowing showing the relationship of the ion source to the torget fixture inside the bell jor. 


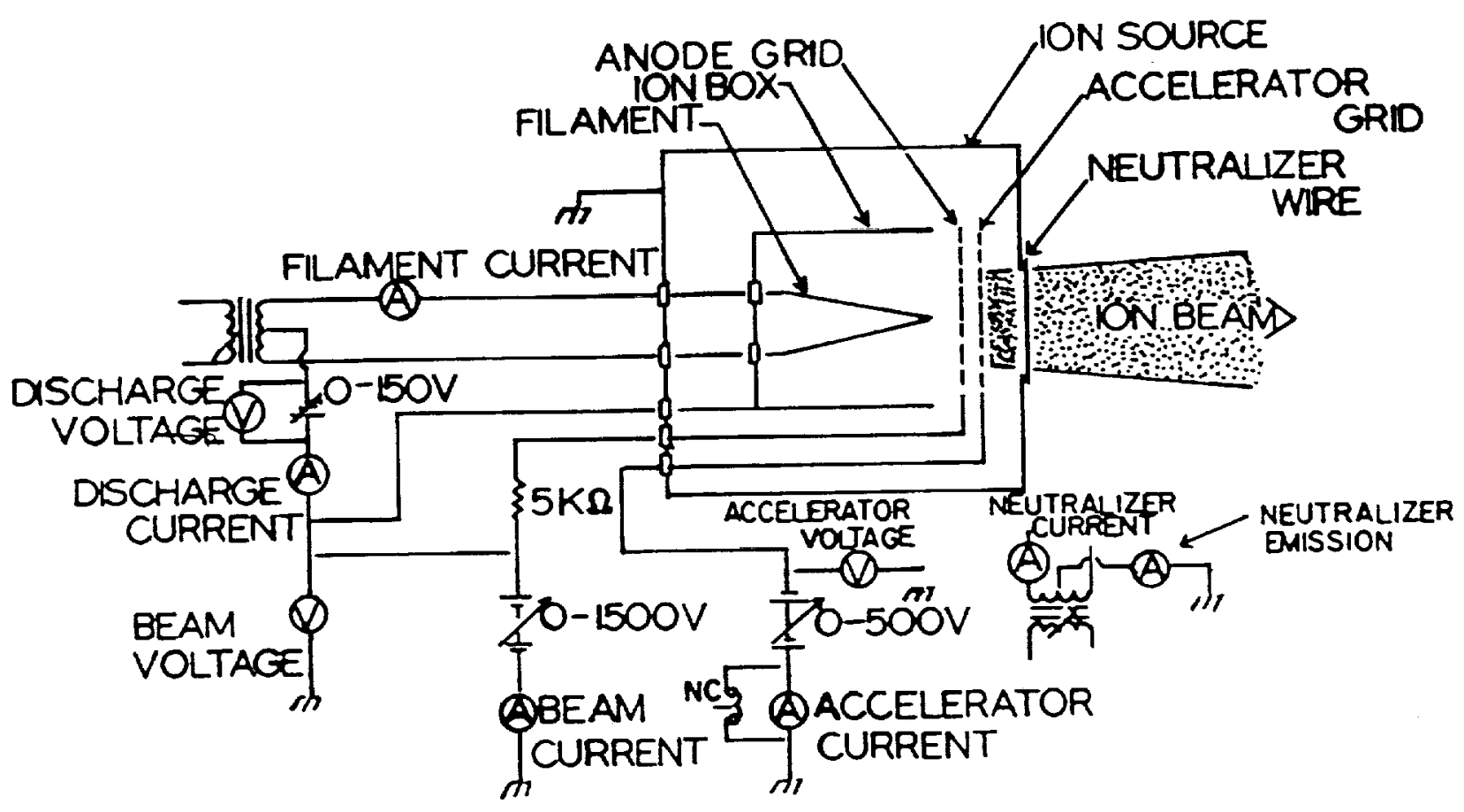

Figure $11-2$ Circuit diagram of the ion source.

electrostatic fields. In general the beam profile was narrow and peaked.

The sample inlet system permitted introduction of two premixed gases into the ion source. The flow rate of each gas was controlled by an MKS flow controller, and the gases used in this work were methane $\left(99.99 \% L_{6}\right.$ and hydrogen (99.99\%). The background pressure was typically $10_{-4}$ torr, and the operating pressure was on the order of $10^{-5}-10^{-4}$ torr.

The target fixture was mounted about $8 \mathrm{~cm}$ from the ion source. Using the present ion source, the directly deposited films were found to be nonuniform. In order to obtain a uniform and large area film, an $X-Y$ scanner was constructed, as shown in Figure II-3. The target plate was able to move approximately \pm $17.5 \mathrm{~cm}$ in two orthogonal directions in a plane perpendicular to the beam. This was accomplished using stepping motors controlled by SLO-SYN indexers (430-PI, superior Electric Co.). The 


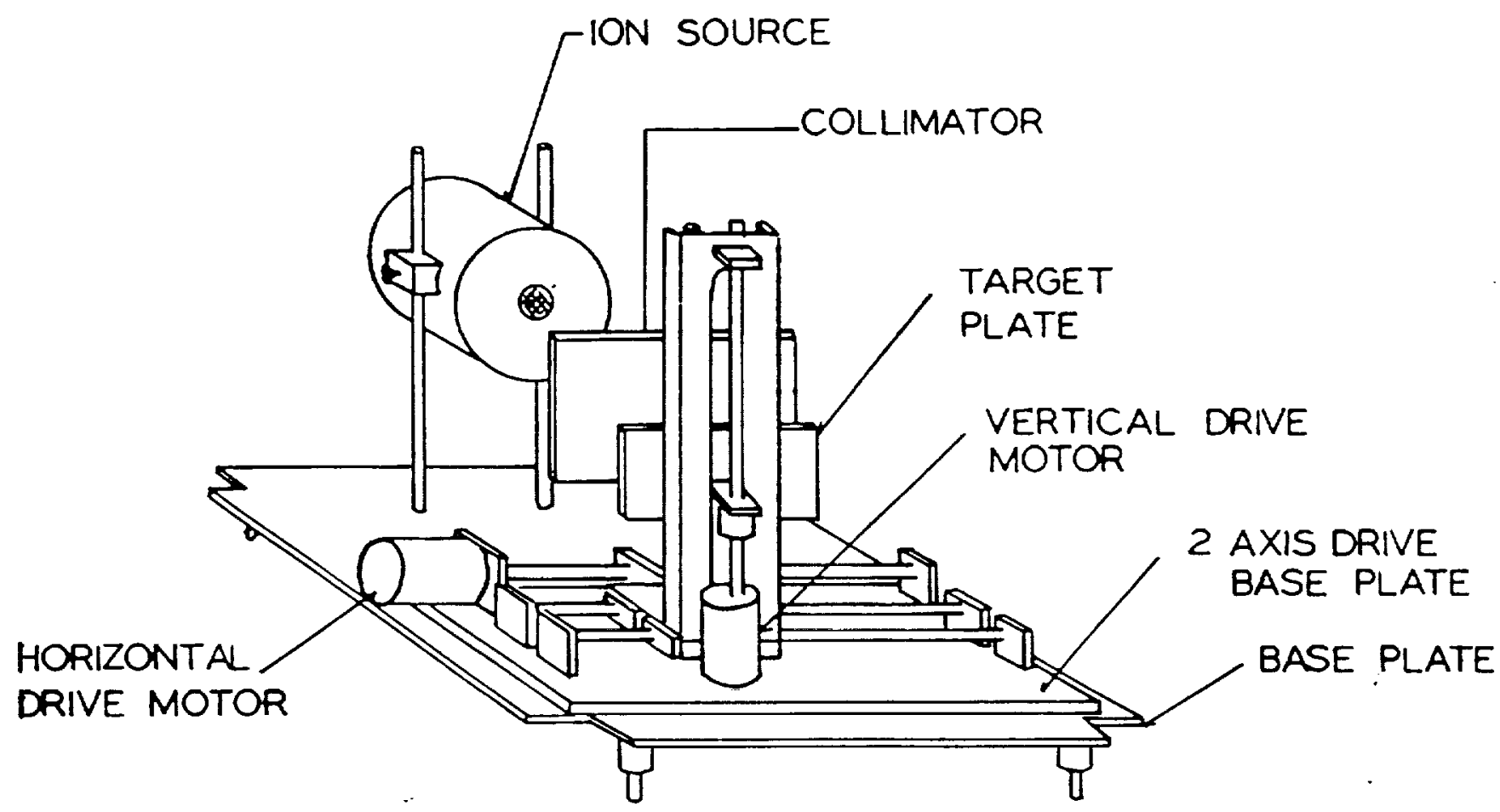

Figure 11-3 Schematic layout of the target sconner.

incexers were interfaced to an IEY XT-compatibie computer via an RS -232 port, which allowed the user to change parameters, i.e., feed-rate and travel distance, in the indexers. Extensive tests were performed to determine the optimum scan rates. The carbon content of the deposited film was then analyzed for uniformity using Rutherford Backscattering across a $5.5 \times 5.5 \mathrm{~cm}^{2}$ area. The optimum conditions were determined to be $0.04 \mathrm{~cm} / \mathrm{sec}$ for the $\mathrm{x}$-direction and $1.6 \mathrm{~cm} / \mathrm{sec}$ for the $\mathrm{Y}$-direction. This set of scan rates was used on all subsequent depositions.

\section{B. RF-PIasma Configuration I}

An If sputtering system was purchased from Cooke Vacuum corporation, consisting of a cryopumped stainless steel bell jar chamber. Inside the chamber were two parallel plate electrodes which were driven by a $13.56 \mathrm{MHz}$, 0 to 500 watt rf generator, and a load matching network.

In configuration $I$, one electrode was grounded, and the other driven by the rf generator. The driven electrode was much 
smaller in area than the grounded electrode, as sketches in Figure II-4. This geometry created an intense piasma acove $=$ i.e driven electrode which was accompanied by a large self-induced $2 c$ bias. Also, a rather diffuse plasma existed at the ground plane with virtually no DC bias. The substrate was placed on tie driven electrode to take advantage of the intense plasma and the high deposition rate. During depositions at low power, the self-induced dc bias was moderate and did not appear to alzer the film characteristics. However, significant high energy ion bombardment of the depositing film occurred. We feel the mair. effect of the ion bombardment was to heat the depositing Eilm and drive out the hydrogen, leaving a low band gas material. This conclusion was based on the results obtained when a deposiz was made at 500 watts rf power, 140 microns torr tozal pressure Eo 30 minutes. Another deposit was made under tie same conaiziss except the discharge was run for 2 minlites ard turned osf for minutes until a total time of 30 minutes depcsition was acrierej. The former deposit exhibited a band gap of approximately $0.28 \%$

the band gap of the latter film was greater than l ey, concarabie to that observed in films deposited at low powers. In vien of this, the cooke system was modified such that the areas of the driven electrode and ground plane were approximately equa: (Configuration II). This eliminated the self-induced bias and the accompanying heating effect. This modified system allones more accurate exploration of the effect of various plasma parameters on the film properties.

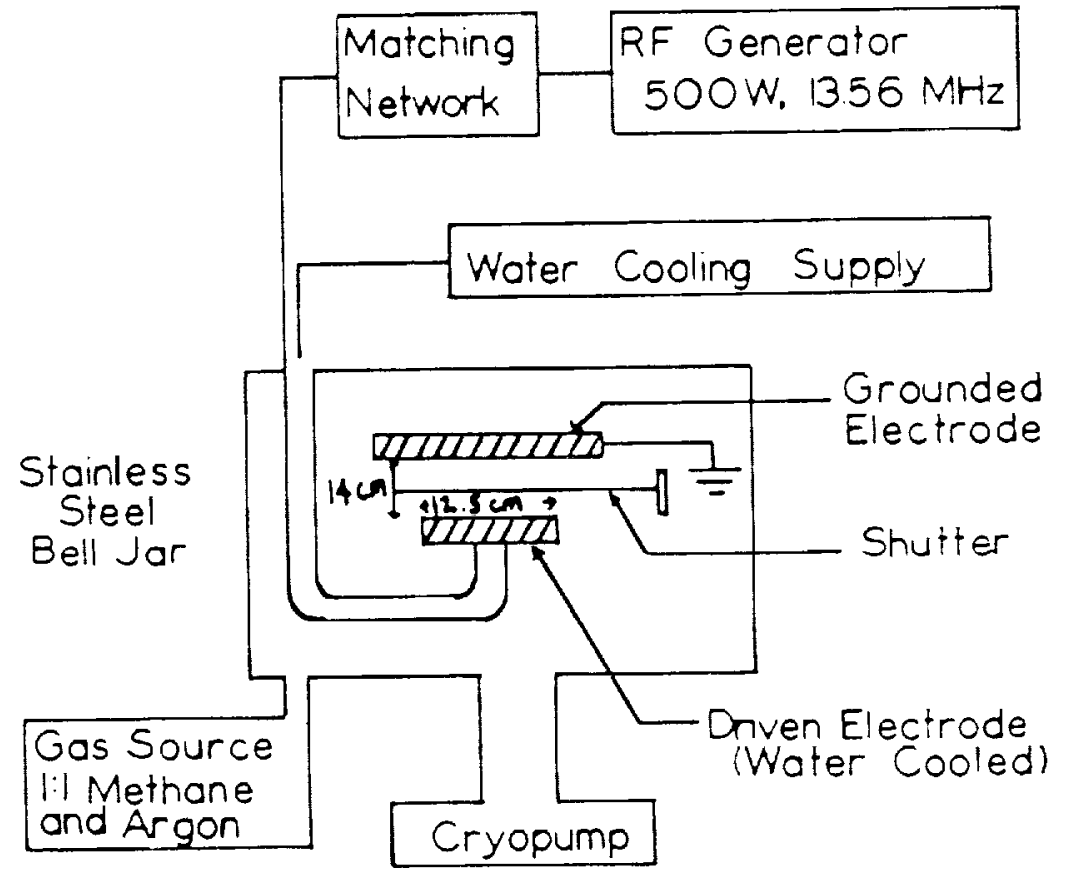

Figure 11-4 Configuration 1

schematic design 


\section{RF-Plasma configurations II and III}

The reason behind the design for this configuration as discussed above was to eliminate high energy ion impact and loss of hydrogen during deposition. This configuration had a $30 \mathrm{~cm}$ diameter stainless cathode on the bottom (Figure II-5), and a 28 cm diameter stainless steel upper electrode with an appropriate ground shield.

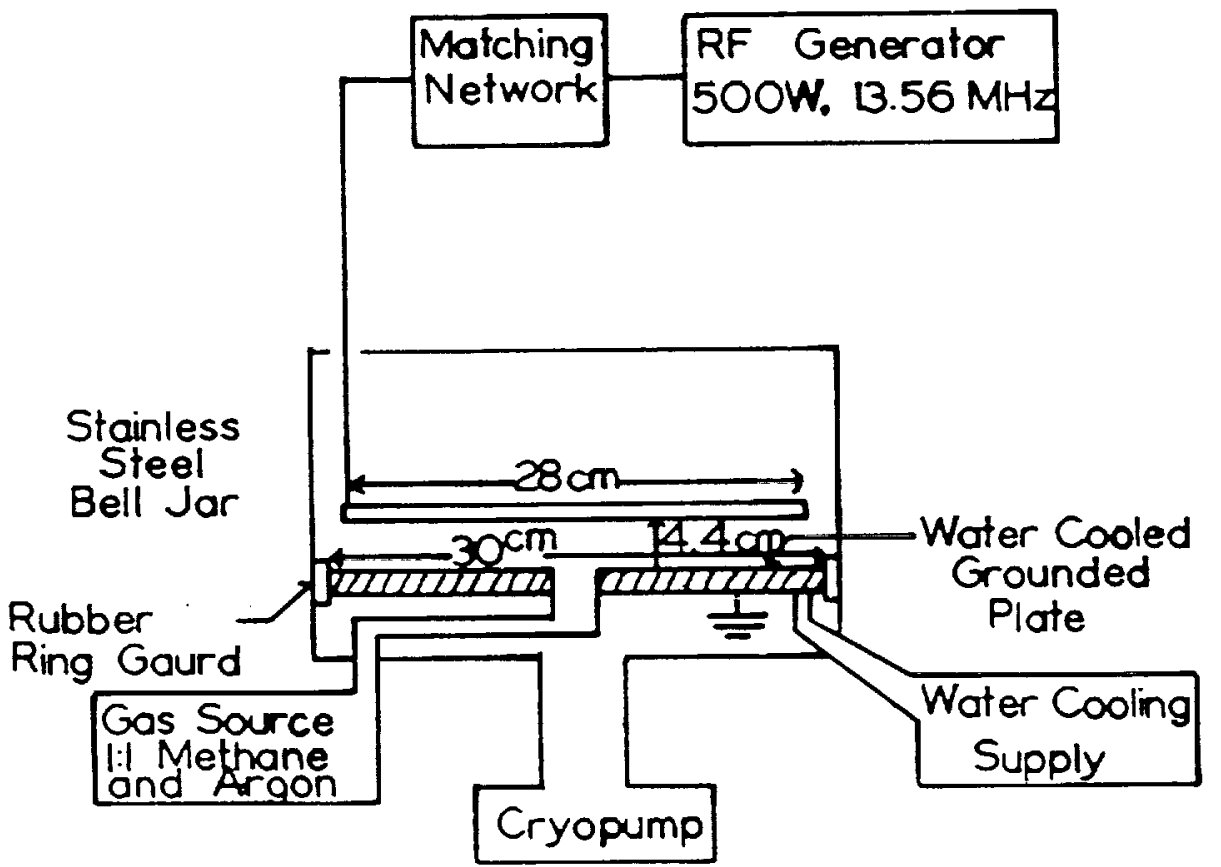

Figure $11-5$ Configuration $\|$ schematic design

The center of the lower grounded electrode was connected to the gas inlet pipe by means of a small plastic tube. A small metal screen was placed over the center of the hole in the lower plate to prevent the gas discharge from igniting in the gas outlet opening. This electrode was also water cooled by a $28 \mathrm{~cm}$ diameter stainless steel plate with copper cooling coils soldered to it.

The Configuration II design reduced the self-induced DC bias, by forcing the area of the driven electrode to be approximately equal to tise area of the ground plate. This reduced the high energy ion bombardment of the depositing film and the subsequent heating effects. This design provided a uniform gas flow over the lowez electrode for a wide range of input gas flow rates and pumping speeds, creating a large area of 
uniform deposition for samples placed on this electrode. A rubber ring guard was placed around the outside of the lower electrode to prevent the discharge from igniting around the edges. The frequency was $13.56 \mathrm{MHz}$.

In Configuration III (used at NASA Lewis) the chamber was similar to II but the plates were of equal area $(20 \mathrm{~cm}$ diameter), and $2 \mathrm{~cm}$ separation. The plasma was pure methane at a pressure of 20 microns. The frequency was $30 \mathrm{kHz}$.

\section{Optimization of Experimertal Parameters}

The physical properties of the DLC films on various substrates were found to be dependent upon the deposition parameters. Optimum deposition parameters, for each technique, were established and are described below.

\section{Ion-Beam Deposition}

An attempt was made to optimize the hydrogen content of DLC films by varying the hydrogen-to-methane ratio inside the ion source. A series of experiments were performed using silicon substrates. The hydrogen concentration was varied from $0 \%$ to 988. The deposition conditions were as follows: beam voltage $1000 \mathrm{~V} ;$ accelerator voltage - $100 \mathrm{~V}$. The discharge voltage increased from $58 \mathrm{~V}$ to $98 \mathrm{~V}$ with increasing hydrogen content in order to maintain the source discharge. The filament current was typically $6 \mathrm{~A}$; neutralizer current typically $6 \mathrm{~A}$ with $3 \mathrm{~mA}$ emission, and the gas flow increased from 1.5 to 10 SCCM with increasing hydrogen content.

The deposited film composition was determined by Rutherford backscattering (RBS) analysis for carbon content and proton recoil detection (PRD) for the hydrogen content. The results are shown in Table II-1. Hydrogen content in the deposited DLC film has been found to be dependent on the hydrogen-to-methane ratio inside the ion source. In particular, increased hydrogen concentration in the ion source has been found to result in an increased hydrogen content in the deposited film. Using pure methane in the process of the present study, the final hydrogen concentration in the DLC film is approximately 308 . With 208 hydrogen in the ion source, the hydrogen concentration in the DLC film is approximately $35 \%$ while with hydrogen concentration in the ion source of between $50 \%$ and $80 \%$, the final hydrogen concentration in the DLC film is approximately $40 \%$ to $41 \%$. Accordingly, variation of the hydrogen concentration in the ion source can be utilized to vary the hydrogen concentration of the deposited DLC film. In general, lower hydrogen concentrations in the DLC film render the coating denser and harder than films having higher hydrogen concentrations. Accordingly, in most applications, the use of pure methane is preferred. 
The effect of ion-impact energy on the film quality (uniformity, pinhole, adhesion, and optical properties), on the deposition rate, and on the damage to the substrate was investigated. Two impact ion-energies of 500 and $1000 \mathrm{eV}$ were used to deposit diamondlike carbon on silicon substrates. A pure $\mathrm{CH}_{4}$ gas was used in these experiments. The ${ }_{5}$ gas flow rate was 3 SCCM and the chamber pressure was $9.0 \times 10^{-5}$ torr. Both films appeared to be uniform and golden in color. The film growth rate, hydrogen content and carbon content were analyzed. The results are shown in Table II-2. Within the uncertainties of the RBS, PRD and Dektak film thickness analyses, the deposition rate and the hydrogen concentration in the film were found to be the same. The cross-sectional transmission electron micrograph of the DLC film at $1000 \mathrm{eV}$ showed no damage on the surface of the silicon substrate. At high energy ion impact, the ion current seemed more intense and the films stuck well to the substrate.

The increase of methane molecules resulted in ion-molecule reactions inside the ion source; higher molecular weights of hydrocarbon ions were produced. The present experigents were carried out at three different pressures: $2.6 \times 10^{-4}$ torr, $9 \times$ $10^{-5}$ torr and $6 \times 10^{-5}$ torr brought about by controling the $\mathrm{CH}_{4}$ flow rate $7.32,3.00$ and 1.32 SCCM. An ion-impact energy of 1080 $\mathrm{eV}$ and silicon substrates were used. Uniform golden color films were observed for deposition pressures of $2.6 \times 10^{-4}$ torr and $9 \times$ $10^{-5}$ torr. However, darker films were obtained using a pressure of $6 \times 10^{-5}$ torr. The carbon and hydrogen content of the films were analyzed, and results are shown in Table II- 3 .

It can be seen that at the lowest pressure, the hydrogen content in the film was slightly increased. Therefore, if harder films have less hydrogen, it is better to use higher methane pressures.

The effect of substrate material (silicon, fused silica, lexan, KG-3, BK-7 glass, $\mathrm{ZnS}, \mathrm{ZnSe}$ and HMF) on DLC $f$ ilm growth rate and film quality was investigated using the same experimental conditions: pure $\mathrm{CH}_{4}$ at flow rates of $3.0 \mathrm{SCCM}, \mathrm{I} \mathrm{KeV}$ ion energy, source pressure of $\frac{4}{9} 10^{-5}$ torr, deposition times from 65 to 450 minutes. All films on the above listed substrates were found to be uniform. The film thicknesses were measured using a Dektak instrument. Table II-4 gives the average, growth rate of DLC on various substrates over an area of $4.9 \mathrm{~cm}^{2}$. These were direct ion beam depositions, with the present $2.5 \mathrm{~cm}$ diameter ion source.

The effect of cleaning the substrate surface frior to ion deposition of the DLC films was studied extensively. Bonding of the DLC film on various substrates was found to be strongly dependent upon the surface cleaning procedures. The initial cleaning procedures included: (1) washing with $1,1,1$ Trichloroethane, (2) washing with acetone, (3) wasting with methanol and finally (4) blow drying by dry nitrogen. All samples were cleaned by these four procedures, except the iexan substrate 
Table II-1. Effect of Hydrogen in the Source Gas on the Carbon, Hydrogen Contents of Direct Ion Beam Deposited Diamondlike Carbon Films

$\begin{array}{lcccc}\text { Sample No. } & \begin{array}{c}\text { of Hydrogen } \\ \text { in the Source }\end{array} & \begin{array}{c}\text { of Hydrogen in } \\ \text { the Film }( \pm 5 q)\end{array} & \begin{array}{c}\text { o Carbon in } \\ \text { the Film }( \pm 5 q)\end{array} \\ \text { DLC - C } & 0 & 30 & 70 \\ \text { DLC } & 140 & 2 & 40 & 60 \\ \text { DLC } & 141 & 5 & 36 & 64 \\ \text { DLC } & 142 & 10 & 38 & 62 \\ \text { DLC } & 143 & 20 & 35 & 65 \\ \text { DLC } & 144 & 50 & 40 & 60 \\ \text { DLC } & 145 & 80 & 41 & \text { NO FILM } \\ \text { DLC } & 146 & 90 & \text { NO FILM } & \text { NO FILM } \\ \text { DLC } & 147 & 90 & \text { NO FILM } & 6 I \\ \text { DLC } & 149 & 95 & 39 & \text { NO FILM } \\ \text { DLC } & 148 & 98 & \text { NO FILM } & \end{array}$

TABLE II-2. Effect of Ion Impact Energy on the Direct Ion Beam Deposited Diamondlike Carbon Films.

$\begin{array}{ccccc}\text { iample No. } \begin{array}{c}\text { Ion Impact } \\ \text { Energy }(\mathrm{eV})\end{array} & \begin{array}{c}\text { \% Hydrogen in } \\ \text { the Film }( \pm 5 q)\end{array} & \begin{array}{c}\text { \& Carbon in } \\ \text { the Film }( \pm 5 q)\end{array} & \begin{array}{c}\text { Film Growth } \\ \text { Rate } / \mathrm{min} \pm 5 \mathrm{~A} / \mathrm{min}\end{array} \\ 871-365 & 1000 & 33.0 & 67.0 & 23 \\ 871-366 & 500 & 37.5 & 63.5 & 25\end{array}$


TABLE II-3. Effect of Methane Pressure on the Direct Ion Beam Deposited Diamondlike Carbon Films.

$\begin{array}{ccccc}\text { Sample No. } & \begin{array}{c}\text { CH4 Source } \\ \text { Pressure (torr) }\end{array} & \begin{array}{c}\text { Flow Rate } \\ \text { (SCCM) }\end{array} & \begin{array}{c}\text { \& Hydrogen in } \\ \text { the Film ( } \pm 58)\end{array} & \begin{array}{c}\text { \% Carbon in } \\ \text { the Film }( \pm 5 \%)\end{array} \\ 871-367 & 6 \times 10^{-5} & 1.32 & 38.4 & 61.6 \\ 871-365 & 9 \times 10^{-5} & 3.0 & 33 & 67 \\ 871-368 & 2.6 \times 10^{-4} & 7.32 & 33.4 & 66.7\end{array}$

TABLE II-4. Diamondlike Carbon Film Growth Rate on Various Substrates.

$\begin{array}{lc}\text { Substrate } & \begin{array}{c}\text { Direct ion beam } \\ \text { Deposition Rate }(\mathrm{A} / \mathrm{sec})\end{array} \\ \text { Lexan } & 11.5 \\ \text { BK-7 } & 8.3 \\ \text { KG-3 } & 8.3 \\ \text { Silicon } & 6.3 \\ \text { Fused Silica, Glass } & 5.7 \\ \text { ZnS, ZnSe } & 6.8 \\ \text { HMF } & 6.8\end{array}$


which used only procedures (3) and (4). It was found that LLC films adhered to $\mathrm{BK}-7, \mathrm{KG}-3, \mathrm{ZnS}$, silicon and lexan substrates quite well, and passed the initial "scotch" tape tests. However, the DLC film on fused silica and heavy metal fluoride glass failed the "scotch" tape tests. Thus an attempt was made to investigate the surface cleaning procedures for HMF glass and fused silica. The substrates of HMF and fused silica were cleaned by procedures (1), (2), (3), and (4), and cleaned again by $1000 \mathrm{eV} \mathrm{Ar}$ ion beam for 20 minutes prior to DIC deposition. The DLC films on both substrates again failed the "scotch" tape test. Another cleaning procedure was tried to clean the surface by washing with methanol and drying using a heat gun or dry nitrogen. The DLC films on both substrates were found to stick well to these substrates. The new cleaning procedure was thus adapted for cleaning of $\mathrm{HMF}$ and fused silica substrates.

In the present ion-beam deposition technique, the temperature of the substrate was constantly monitgred by a temperature tape and was found to be less than $60^{\circ} \mathrm{C}$. Since optical materials can be temperature sensitive, no attempt was made to heat the substrate.

\section{RF Plasma Discharge: Configuration I}

Plasma DLC deposition was extremely successful on glass slides (Thickness $\leq 1$ micron) and Si-wafers. Occasionally there were problems with pinholes when high power was used. At high power (especially 250 and 500 watts), the film quality became significantly degraded, in terms of the uniformity of the film thickness and the ability to adhere to glass. The thickest films spalled off the edges of the glass slides if the power was too high. As measured from UV-VIS absorption measurements on samples deposited on glass slides, the optical energy gap was about 0.2 $\mathrm{eV}$ for the 500-watt sample. Substrate heating was suspected to occur at high rf powers. To test for this postulate, sample K3 was prepared on glass, at 500-watt power, $140 \mathrm{microns}$ pressure, and deposited for 10 minutes ( 1 minute times 10 with 5 minutes cooling interrupt periods in between); the resulting sample had an optical gap of $1.1 \mathrm{ev}$, the same value that occurred when low powers were used. This supported the hypothesis that heating caused the drop in optical gap. All subsequent depositions were made with the plasma on for only a few minutes, then the plasma off for 3 to 5 minutes to permit cooling.

All glass samples were cleaned by washing with the following sequence: 1) 1,1,1,-Trichloroethane, 2) acetone, 3) methanol, 4) deionized water, and 5) dry nitrogen blow. All Lexan samples were cleaned by washing with methanol, followed by deionized water, and finally by a dry nitrogen blow.

We noticed that pinholes in films were caused by segregated granular carbon deposits. The pinholes were exposed after the film was blown with dry nitrogen. These granular carbon deposits were probably formed before reaching the substrate, and were likely caused by the excessive amount of carbon atoms in the gas 
phase (in the plasma). Thus, it was logical to reduce the carbon atom density within the plasma. That could be achieved in two ways: 1) By reducing the pressure, and 2) by reducing the power.

We chose the second alternative. Thus, all samples were made at 25 watts power and 140 microns pressure. The results were highly successful.

\section{Plasma Discharge: Configuration II}

A 1:1 mixture of methane and argon and a $13.6 \mathrm{MHz}$ RF power source, capable of delivering up to 500 watts, were used for the generation of the plasma. The plate areas were made almost equal in order to deliver the power with a minimum DC bias voltage between the plates. The maximum DC vias voltage observed was 550 volts. The lower plate was grounded and the upper plate was driven by an RF power supply. A cryopump was used on the chamber.

When the system shown in Figure II-5 was first designed and operated, the rubber guard ring was not present, and the plasma was very unsteady and sometimes passed beyond the lower ground plate to the bottom of the chamber. Also, sometimes it became difficult to start the plasma; even after using the tesla coil and adjusting the matching network of the RF power supply we could not start the plasma, (at the 80 microns base pressure and the flow rate of $12.5 \mathrm{sccm}$ for both methane and argon). Figure II- 6 shows more details of the Figure II-5 design which permitted easier ignition of the plasma due to a better gas flow geometry. We made 16 small holes in the plate and closed the gap between the lower ground plate and the chamber using a vacuum compatible rubber strip as shown in Figure II-6. The gas thus entered the plasma region through the center and flowed radially outward. We planned to use the external DC INPUT to start the plasma (instead of the tesla coil), but found that after modifying the system, the gas plasma was generated rather easily by increasing the gas pressure to 100 microns. Sometimes, use of a tesla coil in combination with some adjustment of the matching network of the RF power supply was helpful in starting the gas discharge. The plasma was found to be confined within the volume above the lower ground plate.

Except for Si, Lexan, HMF glass, and $\mathrm{ZnS}$, all the substrates were first ultrasonically cleaned using 1,1,1-Trichloroethane; then washed with acetone, methanol, and deionized water successively and finally dried by blowing dry nitrogen. Lexan was ultrasonically cleaned using methanol, washed with deionized water and finally dried using dry nitrogen. HMF surface was found to be deteriorated by the use of any of the organic solvents mentioned previously. Thus, we visually looked for the cleanest surface of HMF, and dried it in flowing dry nitrogen. The Si surfaces were clean as received; therefore we used only 

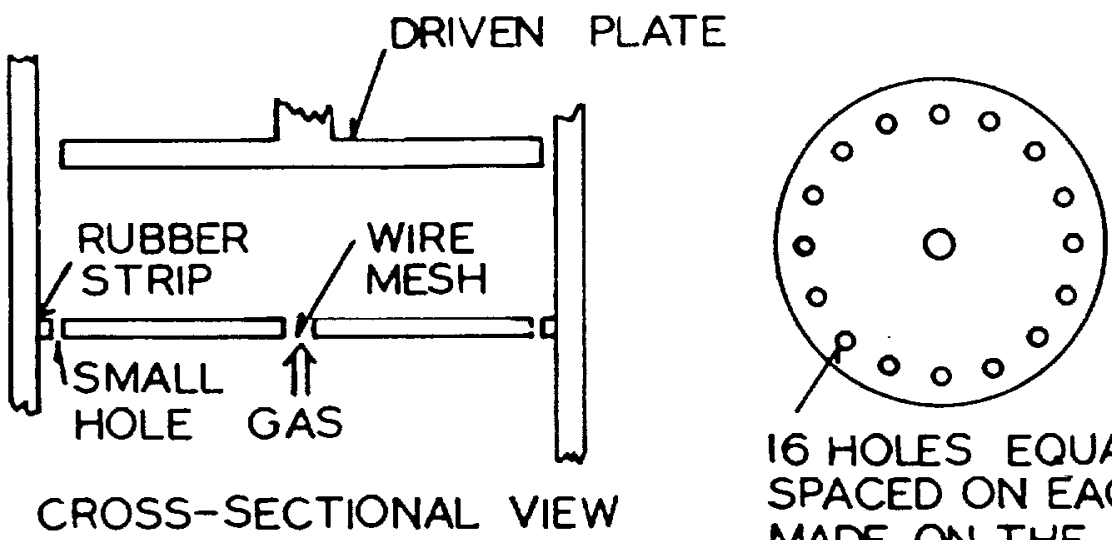

16 HOLES EQUALLY

SPACED ON EACH OTHER MADE ON THE GROUND BASE PLATE.

Figure II-6 Cross-sectional view of the plasma discharge

Configuration 11 .

dry nitrogen to clean them. For $\mathrm{ZnS}$, we followed the same procedure, in order to maximize adhesion.

The best deposition conditions were found to be: 1) flow rate for methane and argon: $13 \mathrm{sccm}$ each, 2) base pressure: 100 microns, 3) power: 200 watts, and 4) DC bias between the two plates: 300 volts.

From the depositions using configuration $I$, we found that DLC films on $\mathrm{zns}$ substrates tended to spall very easily if the film was thicker than a few hundred angstrom units. Because of that, we deposited for 2 minutes (only) on the $\mathrm{zns}$ substrates, resulting in an estimated film thickness of about $300 \AA$. We should note that DLC will adhere to $\mathrm{ZnS}$ and $\mathrm{ZnSe}$ if a thin ( 300 \&) Ge film is deposited between the semiconductor and the DLC layer [6].

\section{4. $30 \mathrm{kHz}$ Plasma Deposition System: Configuration III}

Figures II- 7 and II-8 show the strong dependence of deposition rate on substrate temperature, and on power [7]. The configuration for these depositions was similar to Plasma Deposition Configuration II, described above. The plasma was of pure methane gas at a pressure of 20 microns. $100^{\circ} \mathrm{C}$ substrate temperature and a power level of 200 watts was typical for producing good films. 


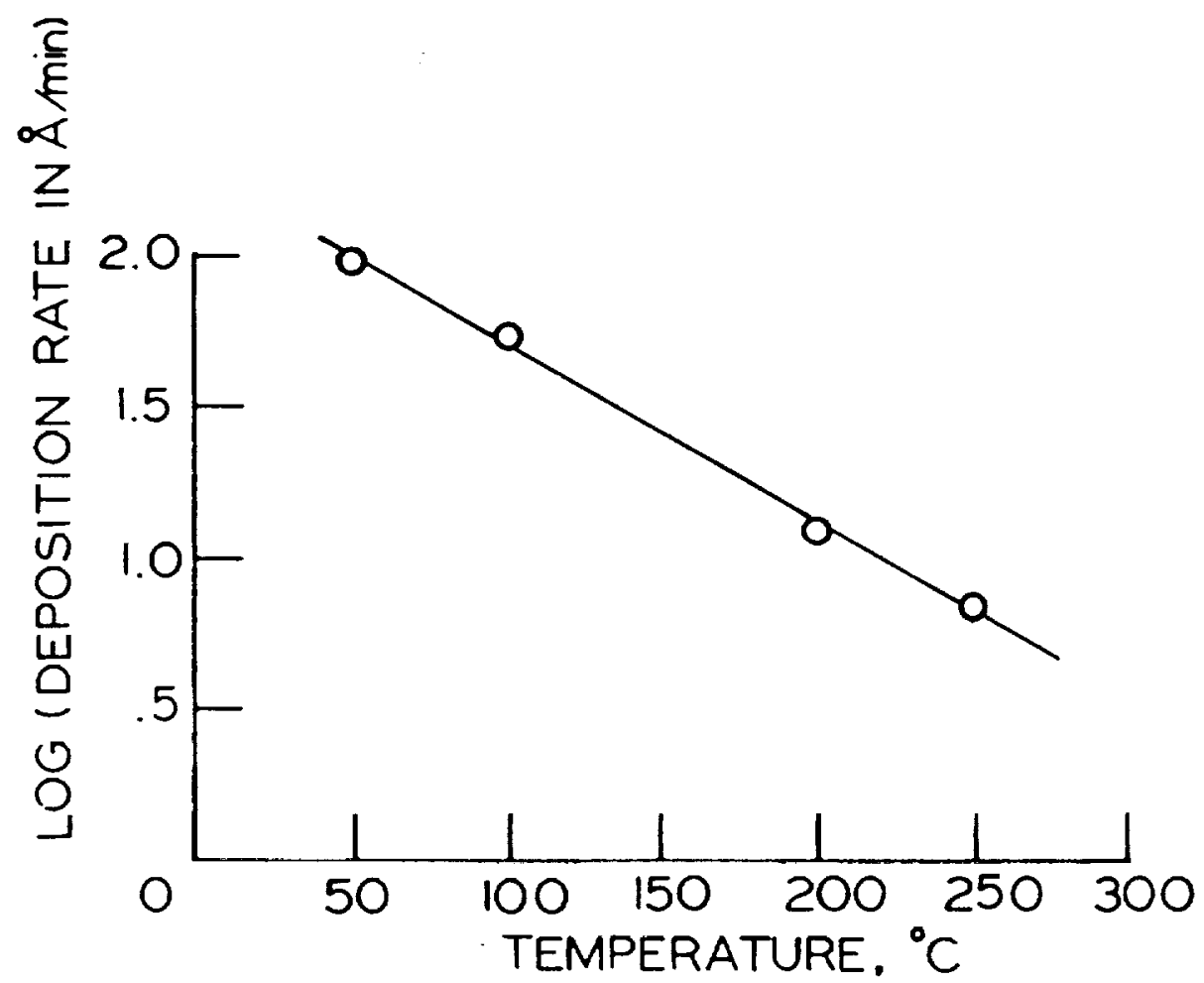

Fig 11-7. Logrithmic plot of deposition rate vs temperature

\section{E. Antireflection Conditions Using DLC}

As mentioned above, substrates of infrared interest on wich we deposited DLC included: lexan, silicon, fused silica, $\mathrm{KG-3}$ glass, BK-7 glass, $\mathrm{ZnS}, \mathrm{GaAs}, \mathrm{Ge}$, and heavy metal fluoride giass. It was desired to know if DLC could be deposited to the proper thicknesses and with the correct indices of refraction for use as an antireflecting coating on each of these substrates.

Antireflecting coatings provide an important method of enhancing transmission through optical window materials [8].

The reflectivity has a minimum when

$$
n_{1} d_{1}=\lambda_{0} / 4
$$

where $n$, is the index of refraction of the coating, and $d_{3} i=s$ thickness. The reflectivity minimum is at its lowest valde (zero) when

$$
n_{1}^{2}=n_{0} n_{2}
$$




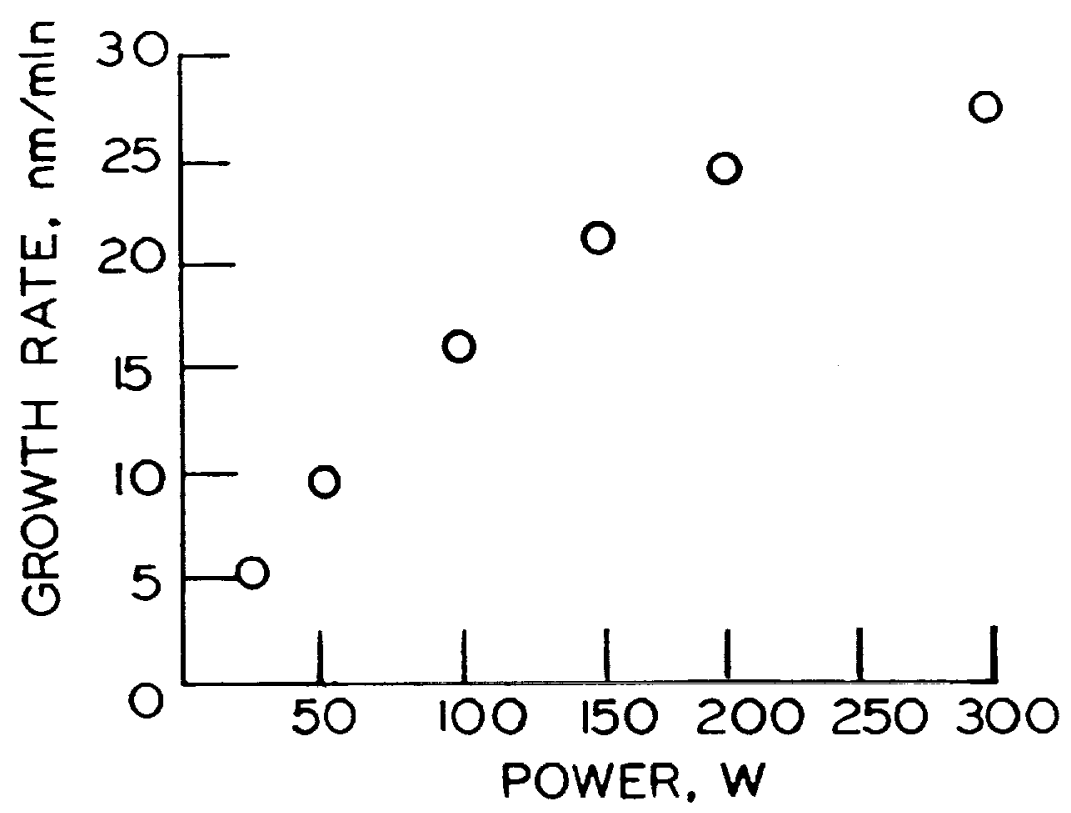

Fig II-8 Growth rate of hydrogenated carbon on $n-\ln P$ as a function of deposition power.

where $n_{0}$ is the index for the ambient, which is normally air, so

$$
n_{1}=\sqrt{n_{2}}
$$

is required, where $n_{2}$ is the index of the substrate at the wavelength of interest.

Table II-I lists infrared transmitting substrates, their indexes of refraction, the operating wavelengths of interest, and the required DLC thickness and optical index of refraction. The proper index came from use of Eq. II-3, and the proper thickness from Eq. II-1.

What is noticed immediately from Table II-I is that the required film index of refraction ranges from 1.2 to 2.85 for the examples listed. 
The index of refraction of DLC can be controlled by choosing the proper deposition technique and parameters [1]. The rar.ge typically found is for

$$
1.6 \leq n_{1} \leq 2.4 \quad \text { II }-4
$$

which makes the optimum matching substrates have indices from

$$
2.5 \leq n_{2} \leq 5.8 \quad \text { II }-5
$$

These values are much higher than the indexes for the glasses under consideration (Table II-I), but result in a decent match for $\mathrm{ZnS}$, diamond, $\mathrm{TiO}_{2}, \mathrm{As}_{2} \mathrm{~S}_{3}$-glass, Se-glass, and results in good matches for Si, Ge, GaAs, and Insb. All are common infrared transmitting materials [9].

In conclusion, we find that with the exception of $z$ ns we were able to directly deposit DLC on the chosen substrates to the desired thicknesses for antireflection. The indexes of refraction were measured from $300 \mathrm{~nm}$ to 10 microns, and found to be in the range from 1.6 to 2.0 . Other workers have prepared DLC samples with indices up to 2.4. Thus, we have established a range of conditions for use of DIC as an antireflecting coating. zerc reflectance can be achieved on substrates of $\mathrm{Si}, \mathrm{Ge}, \mathrm{GaAs}$, and InSb. Low reflectance can be achieved on $\mathrm{ZnS}$, diamond, $\mathrm{TiO}_{2}$ ' As $S_{3}$-glass, se-glass; but DLC will not provide total

antireflecting conditions when deposited on the common glasses with index near 1.5 .

III. Moisture Protection with DLC

\section{A. Introduction}

DLC is amorphous and thus has no grain boundaries through which water might otherwise diffuse. One of the most common uses of thin films is for coatings for moisture protection. Thus DLC seemed to be an ideal candidate material for use as a hermetic seal [5]. Applications, for example, might be to passivate integrated circuits, or to keep water from sensitive infrared transmitting optical windows or lenses.

It is very difficult to measure penetration of liquids into thin films. Common surface analysis techniques such as AUGER, ESCA, and SIMS require ultra high vacuum, and therefore cannot be used.

\section{B. Diagnostics Technigue}

We have shown that variable angle spectroscopic ellipsometry (VASE) can be used to determine the thickness of ultrasmall amounts of water on, and in a thin film [5]. This spectroscopy is 
not commonly known, so a brief description will be given [10]. The interested reader can find more details in references listed.

Ellipsometry determines the ratio of complex reflection coefficient

$$
\tilde{\rho} \equiv \tilde{R}_{p} / R_{s}=\tan \psi \exp j \Delta
$$

where $\tilde{R} p$ and $\tilde{R} s$ are the complex Fresnel reflection coefficients for components of light parallel (P) and perpendicular (S) to the plane of incidence of the incident and reflected light. In our VASE technique, data are taken from 300 to $800 \mathrm{~nm}$ with light incident at an angle $\phi$ to the normal to the sample. The reflected light polarization state is analyzed with a rotating polarizer. Light intensity is measured with a photomultiplier tube, and the signal is digitized and Fourier analyzed to determine the $\psi$ and $\Delta$ parameters of equation III-I.

The measured complex ratio $\tilde{\rho}$ is related to the optical index of refraction, $n$, and extinction coefficient, $k$, of the material under study. 'If complex materials structures are involved, then $n$ and $k$ can be determined for individual layers, and layer thicknesses determined.

Microstructural analysis is performed assuming the nature of the sample under study. For the present samples the model is shown in Fig. III-1. The $t$, are layer thicknesses, and $f_{2}$ is the fraction of DLC in a DLC plas $\mathrm{H}_{2} \mathrm{O}$ Bruggeman effective medium approximation (EMA) mixture layer. The procedure is to calculate using the Fresnel reflection coefficients for a multilayer parallel stack (and EMA mixed layers), for a given initial set of values for thicknesses and fractions. Next, a regression analysis is performed to minimize the mean square error function (MSE) defined by

$$
\text { MSE }=\frac{1}{N} \sum_{i=1}^{N}\left(\psi \exp _{i}^{\exp }-\psi_{i}^{\operatorname{calc}}\right)^{2}+\left(\Delta \exp _{i}^{\exp } \operatorname{calc}_{i}\right)^{2}
$$

where "exp" means experimentally measured, and "calc" means calculated. The psi and delta are functions of wavelength $\lambda$ and angle of incidence $\phi$. A large range of both $\lambda$ and $\phi$ are chosen so that an "overdetermination" of measurements with respect to the number of unknown parameters is made, and correlation problems avoided. In our analysis programs we can use Eq. (III-2) as formulated, or we can use psi alone or delta alone, or the minimization can be done with respect to $\tan \psi$ and $\cos \Delta$. The final outcome is a set of values for thicknesses, EMA fractions, and optical constants for any of the layers. The optical constants can take on several forms: 1) index of refraction $r$. and extinction coefficient $k, 2$ ) real, El and imaginary, E2, parts of the optical dielectric function, or 3) the ampititude, position, and width of Lorentz oscillators. 


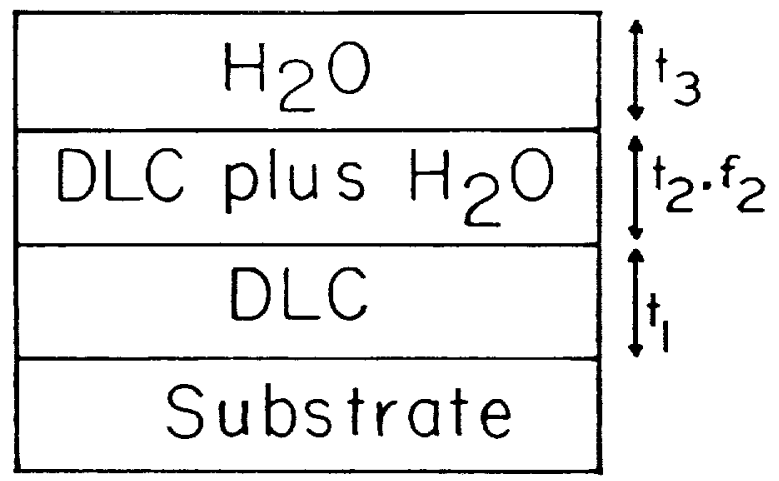

FIG. III-1 Structural model assumed for analysis of

moisture.

$t_{i}$ are thicknesses

and $f_{2}$ is the fraction

of $\mathrm{H}_{2} \mathrm{O}$ in layer 2.

Since we used the Lorentz oscillator model extensively it will be described further. hinen the wavelength-dependent $n, k$ (or E1, E2) values are solved for, the number of unknown parameters equals the number of wavelengths times two, plus the number of layers, plus the number of unknown fractions in an EMA. Thus if 10 wavelengths are used and there are two unknown thicknesses there will be $(2 \times 10)+2=22$ unknowns. In the Lorentz oscillator model there are fewer unknowns, since the following equation represents the spectral dependence of optical constants:

$$
E=1+\sum_{i=1}^{M} \text { Ai }\left(\frac{1}{\lambda+P_{i}+j W_{i}}-\frac{1}{\lambda-P_{i}+j W_{i}}\right),
$$

where $\mathrm{E}$ is the complex dielectric function, and the sum is over the total number of oscillators $M$. For the presently reported work, the maximum number of oscillators used was one. (In section IV the results of a two oscillators analysis are presented). In Eq. (3), $A_{i}, P_{i}$, and $W_{i}$ are the amplitude, position, and width of the ithoscillator, respectively, and $\lambda$ is the photon wavelength. In the oscillator analysis $A_{i}, P_{i}$, and $W_{i}$ thicknesses and EMA fractions are solved for in the pegression analysis. Thus a typical one oscillator DLC analys is has five unknowns: three oscillator parameters and two layer thicknesses; or seven unknowns: three oscillator parameters, three layer thicknesses, and an EMA fraction (see the structural model shown in Fig. III.1).

\section{Samples}

The films of DLC used for moisture penetration studies were prepared using the $30 \mathrm{kHz}$ parallel-plate plasma deposition system (Configuration III) described above [7]. Pure methane and a chamber pressure of 20 microns was used. Power levels of 100 , 200 , and 300 watts were used, but results for 200 watts are reported here. Substrate terperatires ranged from $23^{\circ} \mathrm{C}$ to $250^{\circ} \mathrm{C}$. 
Moisture was introduced to the films in two waysi from immersion in $23^{\circ} \mathrm{C}$ water, and from a steam jet at $100^{\circ} \mathrm{C}$.

\section{Results}

1. As-deposited films

Fig. III-2 shows the dependence of average (over the 300 to $800 \mathrm{~nm}$ range) index of refraction, $\mathrm{n}$ on substrate temperature for films made with a plasma power level of 300 watts. In general the index rises from about 1.7 at low temperature to above 1.9 at high temperature. A measurement of hydrogen content in the film by proton recoil analysis showed that lower hydrogen was present in films with a higher index of refraction [1l]. Measurements of the optical absorption coefficient showed that the bandgap increased with increasing hydrogen concentration. Similar trends have been seen by other workers as well [1].

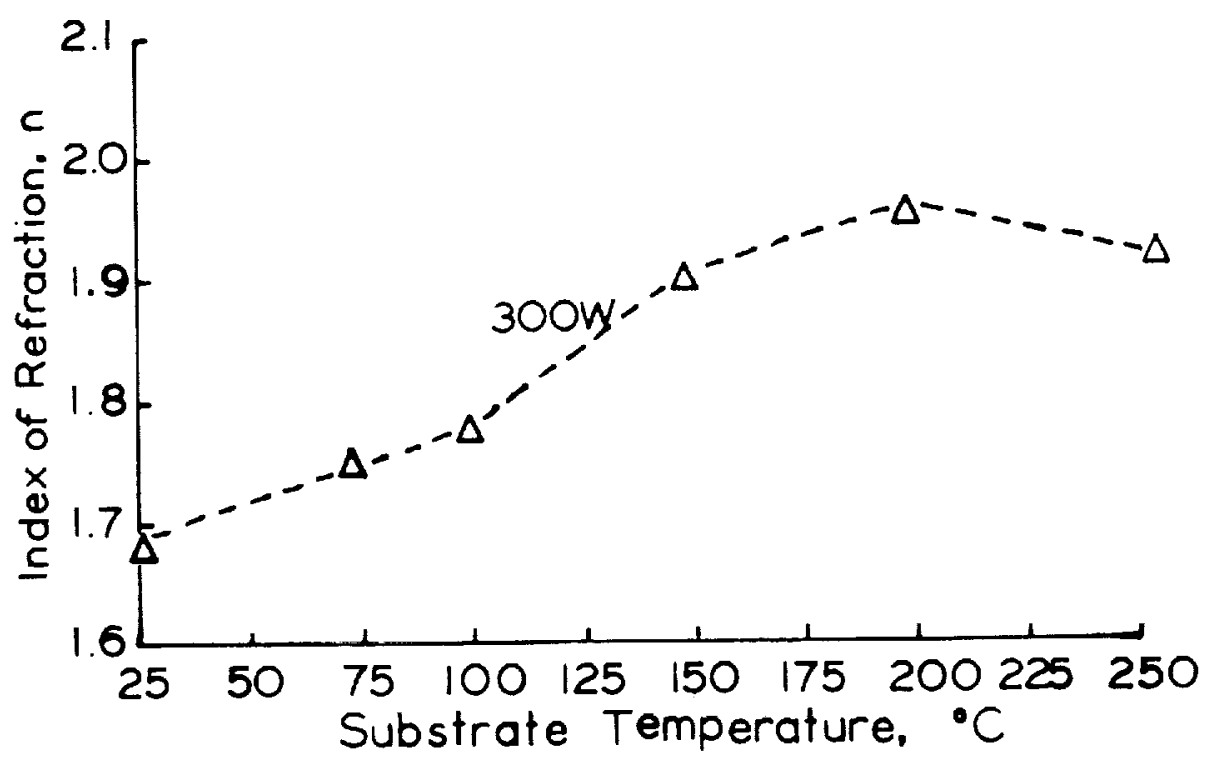

FIG. III-2 Optical index of refraction vs substrate temperature for a power level of 300 Watts.

The environmental stability of DLC films was studied on a large number of samples deposited at various power and temperature values onto polished silicon single-crystal wafers and subjected to immersions in trichlorethane, acetone, ethyl alcohol, sulfuric acid, nitric acid, hydrochloric acid, and hydrofluoric acid. After each immersion samples were subjected to rubber eraser abrasion tests and "scotch tape" pull tests.

These tests served as a comparative measurement. They had no effect on samples deposited with $100 \mathrm{~W}$. For $200 \mathrm{~W}$ and $300 \mathrm{~W}$ depositions there was partial removal for samples deposited at 
room temperature, but there was no effect for substrate temperatures of 74 up to $250^{\circ} \mathrm{C}$. Thus DLC samples prepared under all but a few conditions survived very stressing environmental tests.

\section{Moisture Introduced}

A large number of samples were prepared and investigated for water penetration. The final result was that DIC films were not pentrated by water. The DIC surface had a small amount of roughness, and moisture was found to penetrate the valleys of this roughness, but no further.

Example ellipsometric data are shown in Figure III-3. The data at 0 hours after $\mathrm{H}_{2} \mathrm{O}$ indicate that water was introduced, then the bulk of it allowed to ran off a vertical surface. At this time the maximum amount of vater remained, and the $\Delta$ parameter was lowest. Twenty four hours later some water had evaporated, and $\Delta$ increased. After exposure to a heat lamp much of the water on the surface was evaporated (but not all!). After exposure to the laboratory $23^{\mathrm{C}} \mathrm{C}$ atmosphere a small amount of moisture from the ambient air deposited, with an associated decrease in $\Delta$.

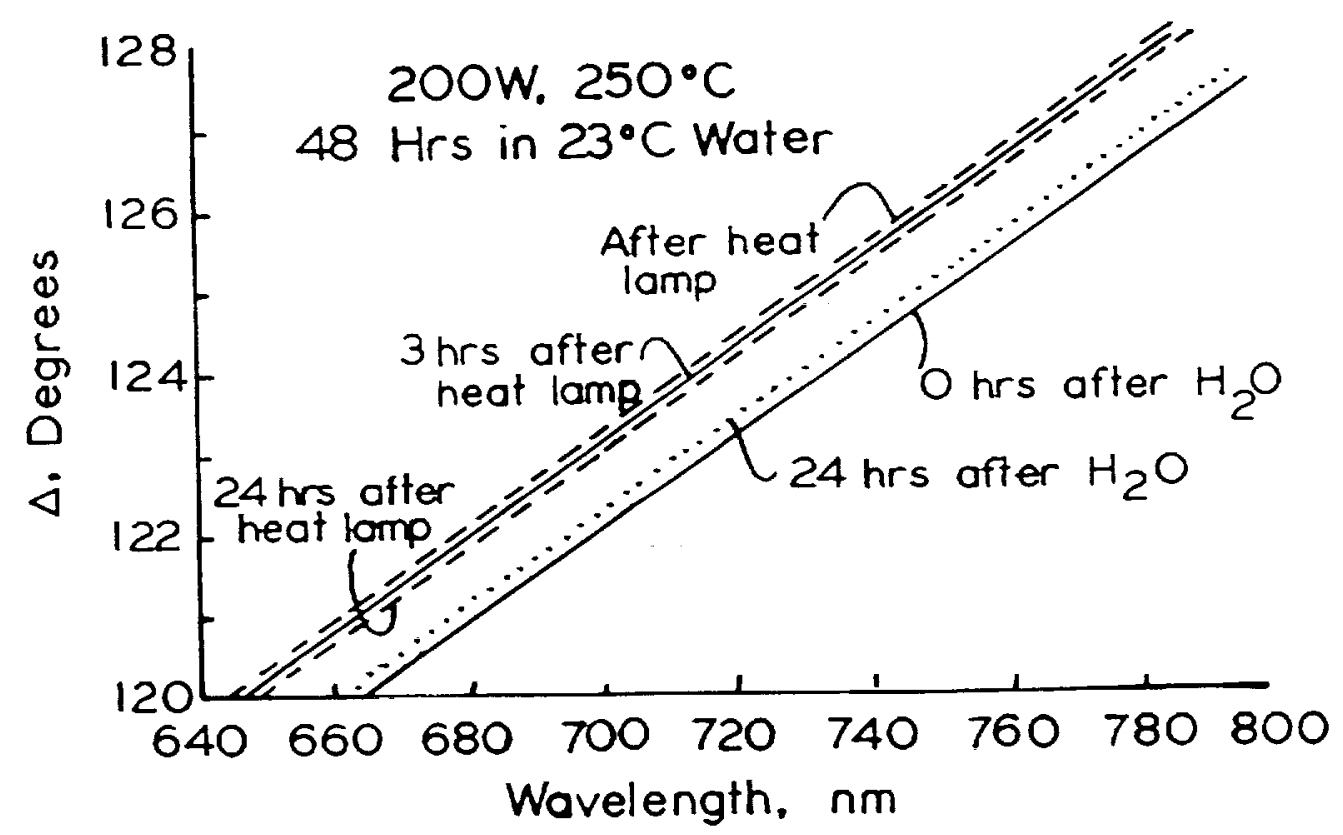

FIG. III-3 Ellipsometric delta parameter vs wavelength at various times after removing the sample from $23^{\circ} \mathrm{C}$ water. Sample was deposited at $200 \mathrm{~W}$, and $250^{\circ} \mathrm{C}$, and soaked in room temperature water for $48 \mathrm{~h}$. After removing from water, it was kept in a room atmosphere.

Using the "oscillator" regression analysis for this sample, and a two-layer ( $t=0$ in Fig. III-l) model in our ellipsometric analysis, we determined that the water layer was $6 E-8$ thick on top 
of a 344- $\AA$ thick DLC film. The three-layer (nonzero $t I, t 2, t 3$, in Fig. III -2 ) analysis was consistent with this result: $330 \AA$ of DLC, $29 \&$ of 50\%-50\% mixture of DLC and water, and $48 \AA$ of pure water on top.

An interesting result was that the heat lamp removed only $12 \&$ of water and that $54 \&$ of water still remained! We propose that this thin water layer was being held to the surface by an unusually high surface tension associated with DLC surface micropores.

A detailed analysis of VASE data for all samples, assuming the model of III.2, was carried out. Tables III.1-4 summarize some of the results.

A summary of the results of DIC moisture studies are that: a) Moisture resided mainly on the surface of DLC independent of water temperature. b) In cases where there was an apparent penetration ( $\leq 50$ \&) it is likely that water was merely filling the void regions of a "rough" surface. The substrates were highly polished oriented single-crystal (semiconductor grade) wafers. $50 \AA$ of roughness layer was reasonable for these materials. C) A heat lamp removed water, but not all of it. This suggests that surface micropores provide a strong surface tension for these very thin water layers. d) The amount of water on the surface after wetting (but without further treatment) did not depend on the parameters of DIC deposition such as power or substrate temperature, nor did it depend on the DLC film thickness in any systematic manner. Thus, DLC protects effectively against moisture penetration [5].

IV. Ion-Beam Modified, Ion-Beam Deposited DLC

\section{A. Introduction}

In this section we present results of variable angle spectroscopic eliipsometric (VASE) studies of ion beam deposited DLC films [11]. These films have been modified by directing 1 $\mathrm{MeV}$ gold ions, as well as $6.4 \mathrm{MeV}$ fluorine ions through the DLC and into the underlying silicon substrates. The percentage of hydrogen in the film was measured vs. fluence using proton recoil analysis. optical analysis was performed assuming the Lorentz oscillator model, using two oscillators with spectral position, width, and amplitude all variable. This model fit the vASE data extremely well. With ion modification the oscillators shifted to lower photon energy, consistent with reduction in hydrogen concentration and possible increased graphitization.

Ion beam modification of DLC films has not been extensively investigated. The purpose of the present work was to study the effects of high energy ion beam irradiation when the ion beam passed through the DLC films. Two ions (gold and fluorine) and a 
Table III-1. 200 Watt, $250^{\circ} \mathrm{C}$ deposited DLC ( 3 layer analysis). $23^{\circ} \mathrm{C}$ water.

$\begin{array}{ccc}\begin{array}{c}\text { DLC } \\ \text { thickness }\end{array} & \begin{array}{c}\text { Mixture }(50-50) \\ \text { layer thickness }\end{array} & \begin{array}{c}\text { Water layer } \\ \text { thickness }\end{array} \\ 330 \AA & 29 \AA & 48 \AA\end{array}$

Table III-2, 200 Watt, $250^{\circ} \mathrm{C}$ deposited DLC, $23^{\circ} \mathrm{C}$ water ( 3 layer analysis).

Condition

No water

$2 \mathrm{~h}$ in water

$4 \mathrm{~h}$ in water
DLC Thickness
Mixture $(50-50)$
layer thickness

-

$24 \AA$

$28 \AA$
Water layer thickness
3268
$326 \AA$
$328 \AA$

$37 \AA$

$51 \AA$

Table III-3. $200 \mathrm{~W}, 250^{\circ} \mathrm{C}$ deposited DLC sample in $100^{\circ} \mathrm{C}$ water ( 3 layer analysis).

\begin{tabular}{|c|c|c|}
\hline Condition & $\begin{array}{c}\text { DLC } \\
\text { thickness }\end{array}$ & $\begin{array}{l}\text { Mixture }(50-50) \\
\text { layer thickness }\end{array}$ \\
\hline
\end{tabular}

No water

$338 \AA$

$2 \mathrm{~h}$ in water

$337 \AA$

$46 \AA$

$36 \&$

$4 \mathrm{~h}$ in water

$339 \AA$

$54 \&$

$56 \&$ 
TABLE III-4. Best fit ellipsometric solutions for indicated samples (steam jet was used to introduce water).

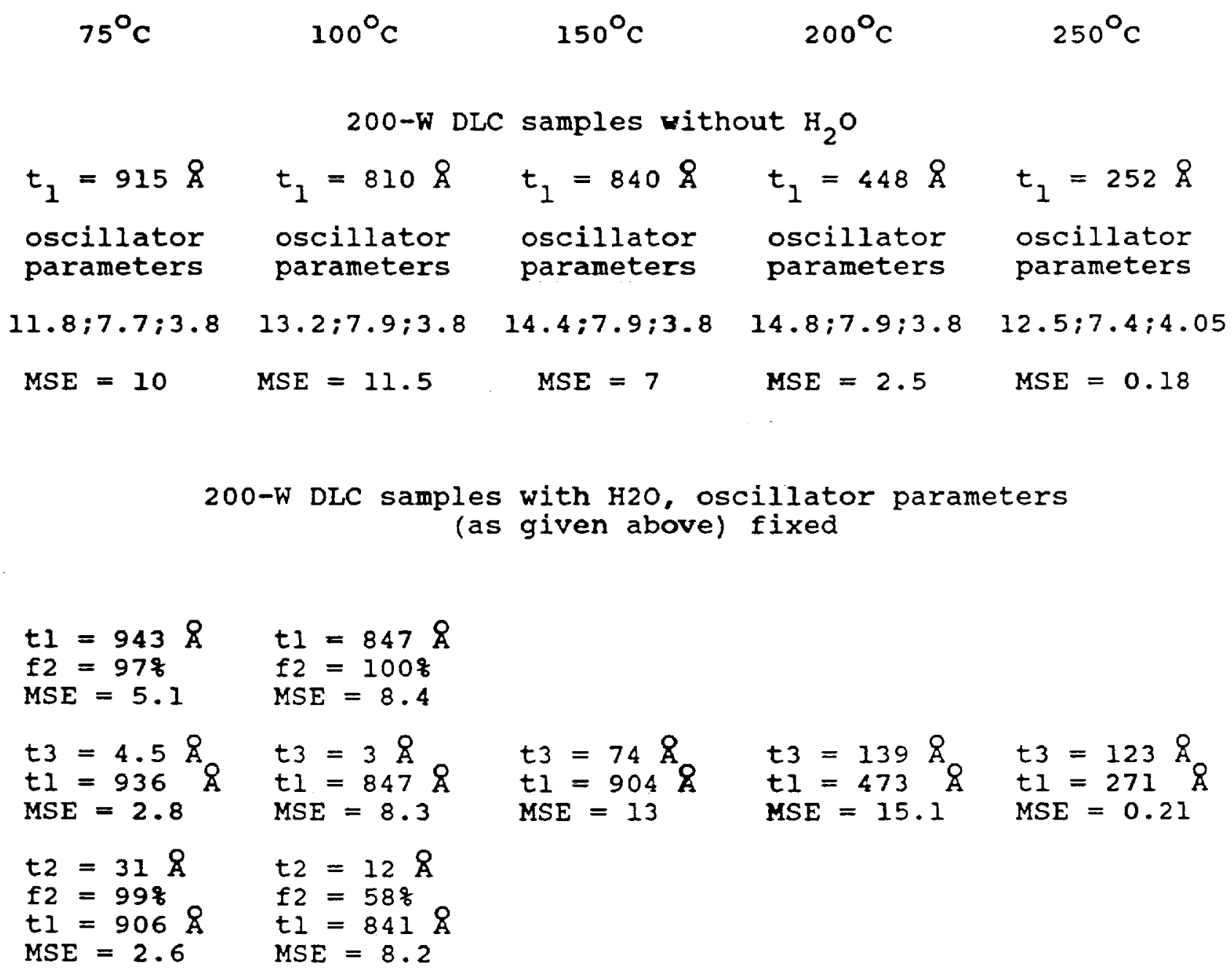


range of fluences were used. Diagnostics techniques included Rutherford Backscattering, proton recoil, hydrogen analysis, and variable angle of incidence spectroscopic ellipsometry (VASE).

\section{B. Experimental}

Samples were prepared in the ion-beam system described in section I above. Methane gas in the $2.5 \mathrm{~cm}$ diameter Kaufman type neutralized ion beam gun system (IonTech Cogporation) was used, and the chamber had a base pressure of $\sim 10^{-7}$ Torr. During
deposition the chamber pressure rose to the range $10^{-4}$ to $10^{-5}$ Torr, and the gas flow rate was $20 \mathrm{sccm}$. In these experiments all substrates were silicon.

Rutherford Backscattering (RBS) and proton-recoil experiments were performed at Universal Energy Systems using a tandem (1.6 MeV) accelerator (Tandetron corp.) which was used to provide $1 \mathrm{MeV}$ gold ions, or $6.4 \mathrm{MeV}$ fluorine ions for the $\mathrm{f}_{2}$ ion beam modifications. Fluences ranged from $3 \times 10^{14} \mathrm{~cm}^{-2}$ to $1 \times 10^{16}$ $\mathrm{cm}^{-2}$.

In the present VASE optical diagnostics, spectral data were taken at several angles of incidence, and the data analyzed with respect to a two oscillator model with all six parameters variable. In addition, the thickness of the DLC film was a variable.

RBS was used to determine the number of carbon atoms per $\mathrm{cm}^{2}$ in each DLC film. Film thicknesses on these same samples were then determined by ellipsometry. From these combined measurements the film density was determined. The limits of error in RBS measurements were approximately \pm 10 percent, and in ellipsometry were \pm 5 percent for DLC films. The combined error of \pm 15 percent covers the range of values measured on all eight samples. Thus we conclude that the density was $1.5 \pm 0.2 \mathrm{gms} / \mathrm{cm}^{3}$ independent of thickness for this set of samples. The density could easily depend on deposition technique and parameter setting, however.

\section{Fluorine $(6.4 \mathrm{MeV})$ Irradiated samples}

Table IV-I summarizes results of ellipsometric analysis of "fluorine-beam" processed DLC on silicon. The shorthand notation has the following meanings: $A, P$, and $W$ are the one oscillator amplitude, position (in ev), and width (in eV), respectively. subscripts I and II refer to first oscillator, and second oscillator in the two oscillator analyses, respectively. "Th" signifies thickness, and the MSE defired by Equation (2) in the last section.

Notice from Table IV-I that irradiation shifted the position of the oscillators to lower photon energy. Another universal trend was for the amplitude in the lower energy oscillator to 
increase with fluence.

Figure IV.I shows the effect of fluorine irradiation on the imaginary part of the dielectric function, E2, analyzed allowing all six oscillator parameters as well as the film thickness to be variables in the regression analyses. The trends are obvious: a downward shift of the E2 maxima in energy, and an increase in the E2 amplitude. At the same time, the higher energy oscillator position decreases (Table IV-I).

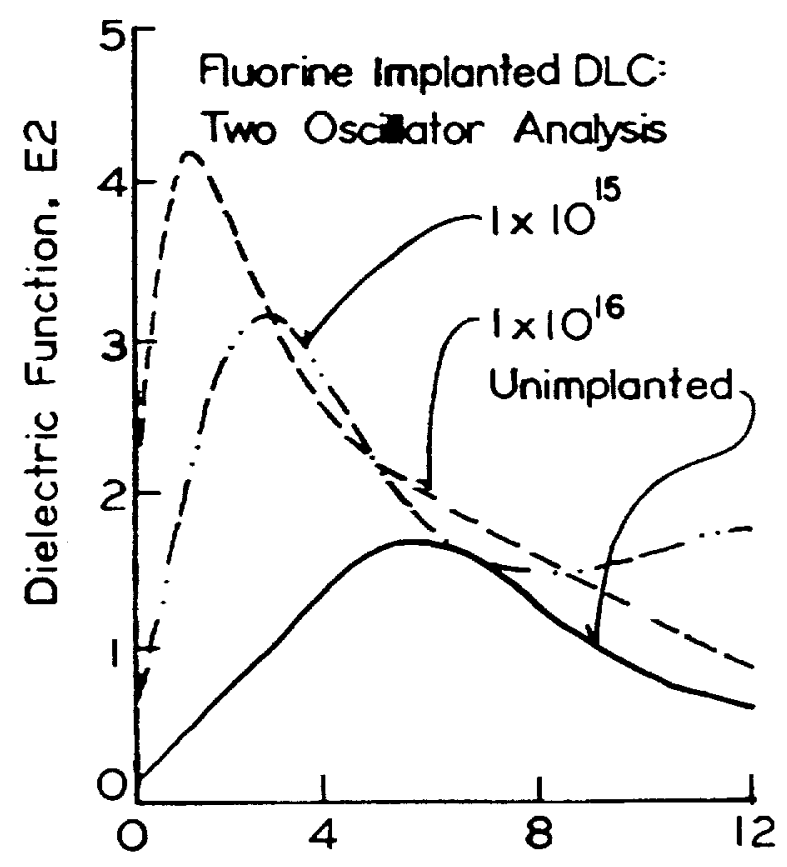

Photon Energy, eV

FIG. IV-1 Imaginary part of dielectric function, $E_{2}$, for Fluorine Implanted DLC: Two Oscillator Analysis.

In Figure IV.2 the real part of the dielectric function El is shown. Again there are shifts to lower energies, and an increase in the amplitude of El.

The extinction coefficient, $k$, vs. wavelength for the various fluences are shown in Fig. IV.3. Note the general rise in magnitude of $\mathrm{k}$ with increasing fluence. This general increase in $k$ with fluence gives rise to a decrease in optical bandgap, and a decrease in hydrogen content, as determined by proton recoil. The main effects of fluence of both the fluorine and gold species on hydrogen content are shown in Figure IV.4. A nearly linear relatior.ship between energy gap and hydrogen content was found. 


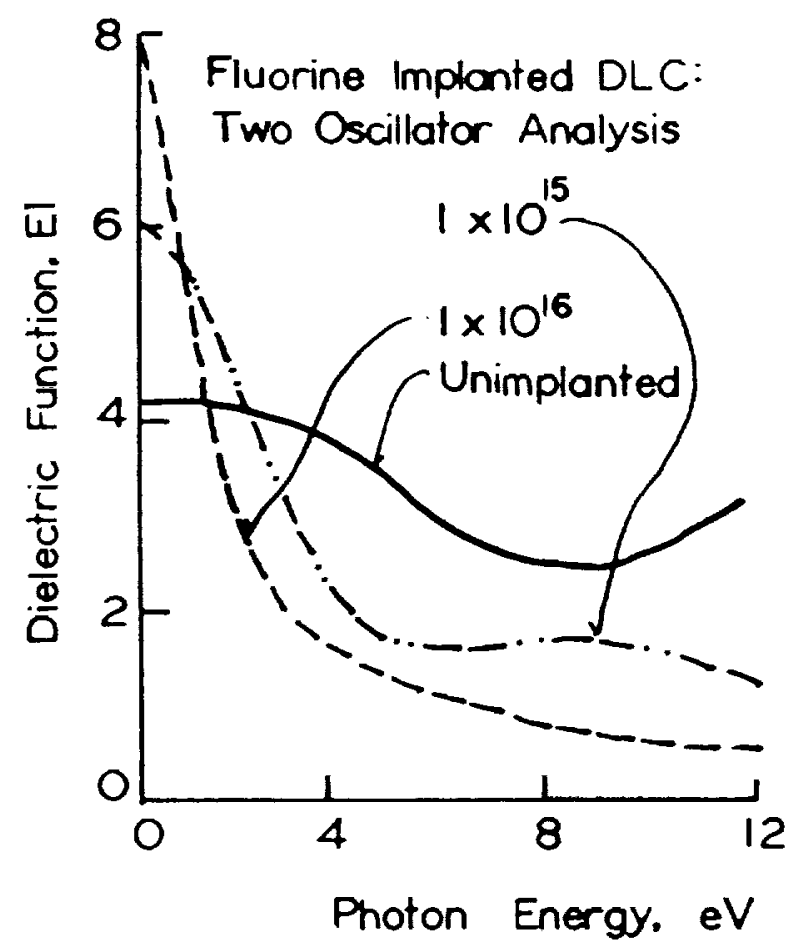

FIG. IV-2 Real part of dielectric function, $E_{1}$, for Fluorine Implanted DLC: Two Oscillator Analysis.

\section{Gold (IMeV) Irradiated Samples}

Results of ellipsometric analysis of samples irradiated with gold ions are shown in Table IV.2. A two oscillator model was used, with all six oscillator parameters variable.

Again there are downward shifts in the oscillator positions with increasing fluence. Other trends were less obvious. By fitting data over our spectral range of 300 to $800 \mathrm{~nm}$, the oscillator analysis allowed us to extend our knowledge of the optical constants over a wider range (with an admitted danger of errors far from the measured range). The results show that the two oscillator model is appropriate for both $F$ and $A u$ irradiation. In both cases the downward shifts are consistent with there being a loss of hydrogen, a decrease in the optical gap, and a tendency towards graphitization. 
Table IV-I. Comparisor resuits of 2-oso. model analysis for F-implanted ( $4.6 \mathrm{MeV}$ ) DIC ior beaII depositec samples (-fit only: $u=$ unimplanted, $I=$ implanted). Except for thicknesses, all units are electron volts. fluence, $\mathrm{cm}^{-2} \mathrm{sec}$.

\begin{tabular}{|c|c|c|c|c|c|c|c|c|}
\hline & \multirow[t]{2}{*}{ 1st } & \multicolumn{2}{|c|}{ oscillator } & \multicolumn{3}{|c|}{ 2nc oscillator } & \multirow{2}{*}{ TK (\&) } & \multirow{2}{*}{ MSE } \\
\hline & & PI & WI & AII & PII & WII & & \\
\hline 0 & 7.5 & 5.58 & 4.0 & 12.2 & $17 . \div$ & $0 . \$ 4$ & $122 I$ & 1.22 \\
\hline 3 & 10.4 & 3.4 & 3.6 & 8.37 & 14.5 & 1.64 & 1307 & 0.13 \\
\hline 10 & 11.1 & 2.56 & 2.92 & 10.22 & 12.8 & 6.0 & 790 & 0.015 \\
\hline 30 & 12.8 & 2.49 & 2.92 & 8.6 & 11.0 & 7.8 & 757 & 0.1 \\
\hline 0 & 22.6 & 0.68 & 2.28 & 18.7 & $4.5 \pi$ & 7.8 & 2624 & 0.47 \\
\hline
\end{tabular}

Table IV-2. Results of 2-oscillator mocels for Au ( $1 \mathrm{MeV}$ ) -implanted DLC ion beam deposited samples ( $\mathrm{U}=$ unimplanted, I = implanted). Except for thigknesses, all units are electron volts. $\quad$ fluence, $\mathrm{cm}^{-2}$ sec.

2-oscillator model

\begin{tabular}{|c|c|c|c|c|c|c|c|c|}
\hline & 15 & oscilla & & $2 \pi d$ & oscillat & & $c$ & MSE \\
\hline & AI & Position & WI & AII & Position & WII & & \\
\hline 0 & 3.34 & 4.33 & 1.45 & 17.0 & 16.7 & $0 . \equiv 5$ & $2832 \AA$ & I. 18 \\
\hline 3 & 1.40 & 3.24 & 0.78 & 21.4 & $\square 5.5$ & 0.29 & $2096 \AA$ & 2.60 \\
\hline 10 & 3.60 & 3.53 & 1.38 & 9.9 & 11.6 & 1.70 & $=173 \AA$ & C. 34 \\
\hline 30 & 3.50 & 3.44 & 1.53 & 9.7 & 3.2 & 2.30 & $913 \%$ & 0.26 \\
\hline 00 & 3.29 & 3.33 & 1.18 & 12.5 & 10.8 & 1.21 & $=314 q$ & 0.77 \\
\hline
\end{tabular}




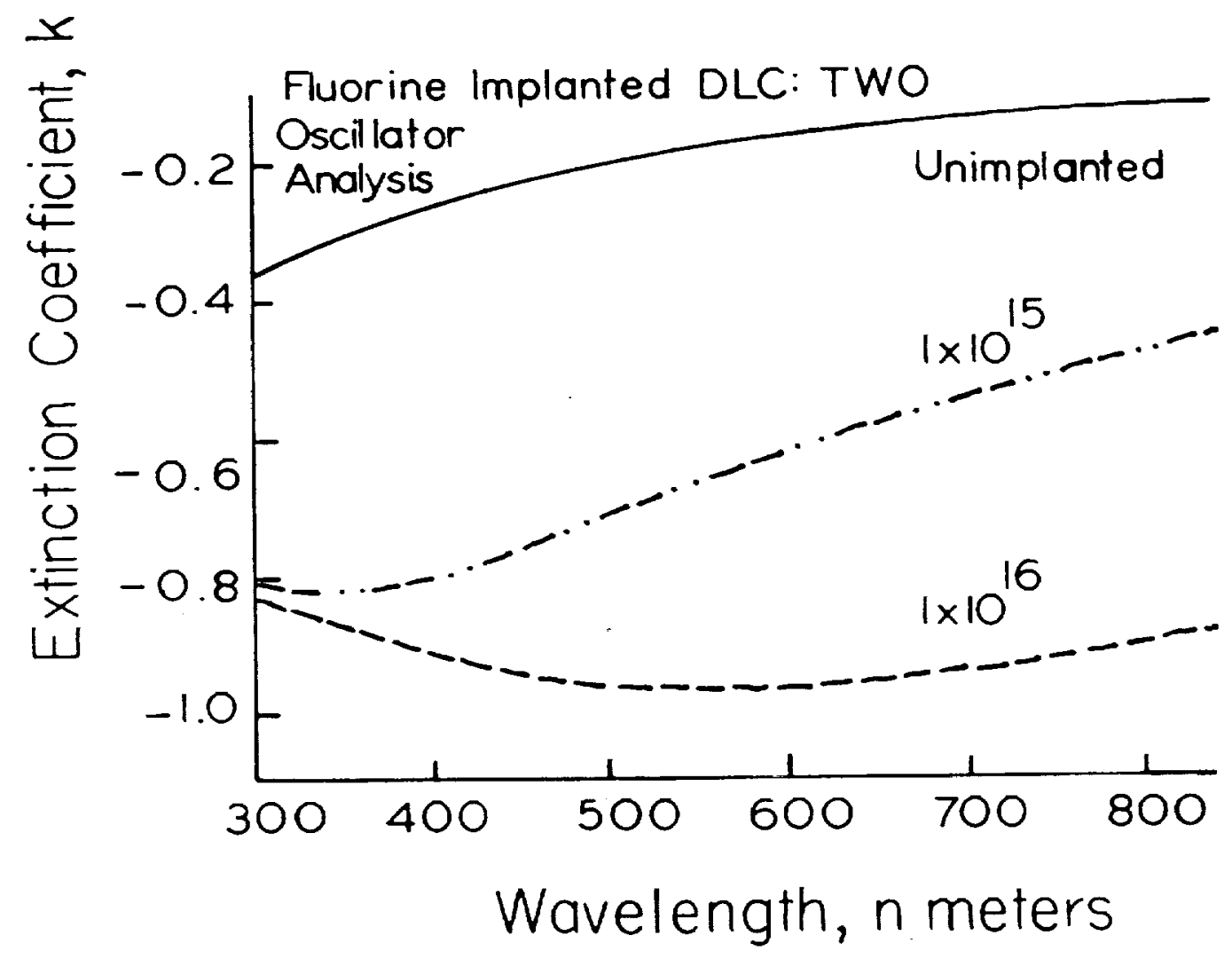

FIG. IV-3 Extinction Coefficient, for Fluorine Implanted DLC: Two Oscillator Analysis. 


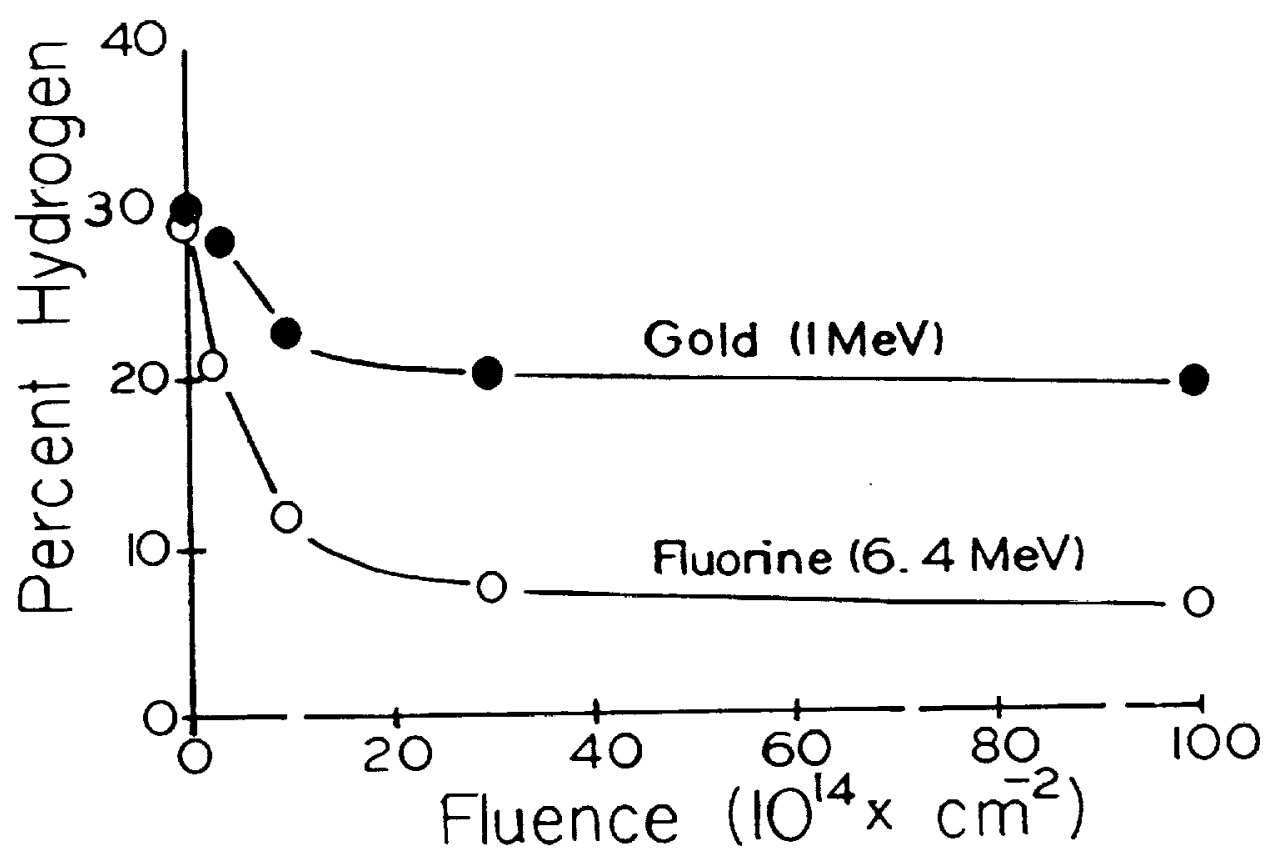

FIG. IV-4 Hydrogen concentration for Au and $F$ implanted DLC.

For gold implants, an optical gap slightly above $1 \mathrm{eV}$ is seen to decrease to about $1 \mathrm{eV}$ with increasing fluence. The effect of irradiation on bandgap isn't as great for $\mathrm{Au}$ as it is with F irradiation. However, the loss of hydrogen with gold fluence was not as great as it was for fluorine.

\section{E. Discussion of Results}

We found that irradiation with a lighter ion (F) at $6.4 \mathrm{MeV}$ through a DLC film (composed of light elements) had a greater effect on the hydrogen content and optical properties of DLC than did $\mathrm{Au}$ irradiation a $=1 \mathrm{MeV}$.

In general a two oscillator mociel yielded an excellent fit to the optical cata, and the two oscillators were centered near 5 $\mathrm{eV}$ and $17 \mathrm{eV}$ in the unirradiated sarples. These positions shift to lower photon energies with fluence, and proton recoil experimerts show that the hydrogen content decreased from rear 30 ( in unirradiated majericis) to neaz 20 s ( $\mathrm{Au}$ ), or rear 6 c (इ) with fluence. The loss $c \equiv$ hycirogen was sot linear :ith flience: 
rather there was a near "saţuration" of the irradiation effects for fluences above $10^{15} \mathrm{~cm}^{-2}$. We believe that at high fluence the ion beams introduced defect centers produced by electronic energy loss which acted to retrap part of the hydrogen. The magnitude of this effect was reduced with increasing ion mass as the proportion of nuclear to electronic energy loss was increased.

It has been argued [13] from optical absorption, Raman, conductivity, and ESR experiments that irradiation at first had only the effect of lowering the hydrogen content, and then at high fluences it increased the graphitic component in their glow discharge produced carbon films. Similarly, we found a linear relationship between optical bandgap and hydrogen content. However, their $50 \mathrm{keV}$ carbon ions were implanted to a depth of only $100 \mathrm{~nm}$. Rather than the "saturation" effects that we saw, they observed a continuing decrease jin hydrogen to less than a few percent at a fluence of $10^{17} \mathrm{~cm}^{-2}$.

The tendency towards lower hydrogen concentration and lower optical gaps was similar to the trend seen with annealing. (The presently reported irradiations were carried out using a cool substrate and low beam currents, so sample heating was not a problem). Thus there appears to be an analogy between the physical effects of irradiation and those of annealing. 


\section{$\underline{\text { References }}$}

1. J.C. Angus, P. Koidl, and S. Domitz, in Plasma Deposited Thin Films, edited by J. Mort and F. Jansen (CRC, Boca Raton, FI, 1986). Chapter 4 .

2. R.L.C. Wu, D.C. Ingram, and J.A. Woollaw, Final Report: "Diamondlike Carbon Coatings for Optical Systems", U.S. Army Materials Technology Laboratory, Contract No. DAAL04-86-C-0030, october 1988.

3. J.A. Woollam, S. Orzeszko, B.N. De, N.J. Ianno, A.R. Massengale, J.J. Pouch, and S.A. Alterovitz, "Diamondlike Carbon Dielectrics for Integrated circuits", Final Report, Control Data Corporation, December 1987.

4. J.A. Woollam, B.N. De, L.Y. Chen, J.J. Pouch, and S.A. Alterovitz, MRS Proceedings Volume: Optical Materials: Processing and science, 1989.

5. S. Orzeszko, B.N. De, J.A. Woollam, J.J. Pouch, S.A. Alterovitz, and D.C. Ingram, J. Appl. PhYs. 64, 4175 (1988).

6. M.J. Mirtich, D. Nir, D. Swec, and B. Banks, J. Vac. Sci. Technol. A4, 2680 (1986).

7. J.J. Pouch, S.A. Alterovitz, J.D. Warner, D.C. Liu, and W.A. Lanford, Mat. Res. Soc. Symp. 47, 201 (1985).

8. H.J. Hovel, "Solar Cells", in Semiconductors and semimetals, 11 , edited by R.K. Willardson, and A.C. Beer, Academic Press, New York, 1975, p. 203.

9. The Infrared Handbook, edited by W.L. Wolfe, and G.J. Zissis, The Infrared Information and Analysis Center, Environmental

Research Institute of Michigan, Ann Arbor, MI, 1978.

10. J.A. Woollam, P.G. Snyder, and M.C. Rost, Thin Solid Films $166,317(1988)$.

11. S. Orzeszko, J.A. Woollam, D.C. Ingram, and A.W. McCormick, J. Appl. Phys. 64, 2611 (1988).

12. S. Prawer, R. Kalish, M. Adel, and V. Richter, J. Appl. Phys. 61, 4492 (1987).

13. M.E. Adel, R. Kalish, and S. Prawer, J. Appl. Phys. 62, 4096 (1987). 